Suliman Nakhal, Dennis Wiedemann, Bernhard Stanje, Oleksandr Dolotko, Martin Wilkening, Martin Lerch

\title{
LiBi3S5-A Lithium Bismuth Sulfide with Strong Cation Disorder
}

Article, Postprint version

This version is available at http://dx.doi.org/10.14279/depositonce-5479

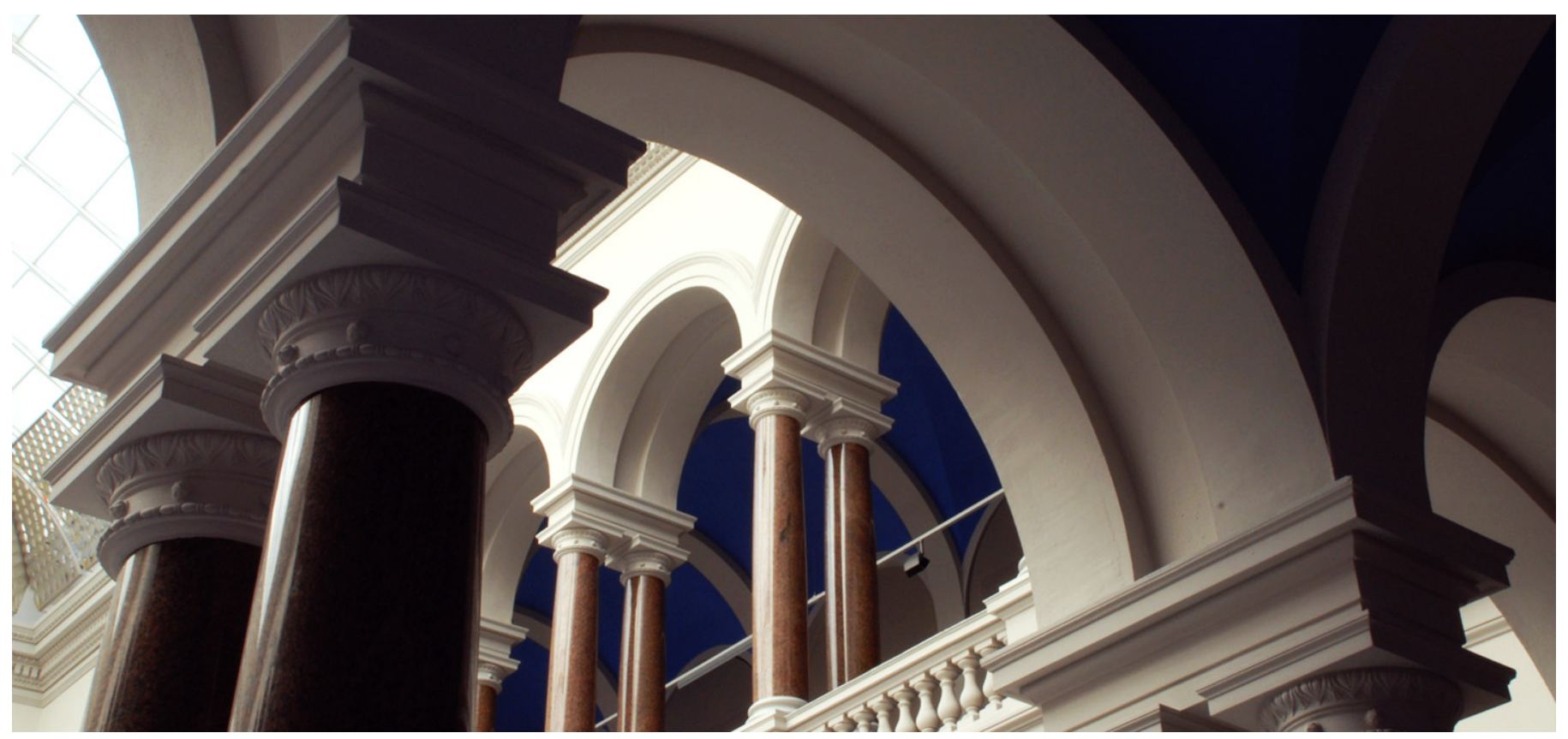

\section{Suggested Citation}

Nakhal, Suliman et al.: LiBi3S5-A Lithium Bismuth Sulfide with Strong Cation Disorder. - Journal of solid state chemistry. - ISSN: 1095-726X (online), 0022-4596 (print). - 238 (2016), June. - pp. 60-67. - DOI: 10.1016/j.jssc.2016.03.010. (Postprint version is cited, page numbers differ.) 


\title{
$\mathrm{LiBi}_{3} \mathrm{~S}_{5}-\mathrm{A}$ Lithium Bismuth Sulfide with Strong Cation Disorder
}

\author{
Suliman Nakhal ${ }^{a}$, Dennis Wiedemann ${ }^{a,{ }^{*}}$, Bernhard Stanje $^{b}$, Oleksandr Dolotko ${ }^{c}$, \\ Martin Wilkening ${ }^{b}$, Martin Lerch ${ }^{a}$ \\ ${ }^{a}$ Institut für Chemie, Technische Universität Berlin, Straße des 17. Juni 135, 10623 Berlin, Germany. \\ ${ }^{\mathrm{b}}$ Christian Doppler Laboratory for Lithium Batteries and Institute for Chemistry and Technology of Materials \\ (Member of NAWI Graz), Graz University of Technology, Stremayrgasse 9, 8010 Graz, Austria. \\ ${ }^{\mathrm{c}}$ Heinz Maier-Leibnitz Zentrum (MLZ), Technische Universität München, Lichtenbergstraße 1, 85748 Garching \\ b. München, Germany.
}

\begin{abstract}
Among chalcogenide semiconductors for thermoelectric applications, alkali-metal bismuth compounds occur in many complex compositions favorable for high performance. Although $\mathrm{LiBi}_{3} \mathrm{~S}_{5}$ had been announced in 1977, the potential 1D lithium-ion conductor has hitherto eluded selective synthesis and structure determination. In this study, we present a solid-state route to phase-pure $\mathrm{LiBi}_{3} \mathrm{~S}_{5}$ powder starting from $\mathrm{LiBiS}_{2}$ and $\mathrm{Bi}_{2} \mathrm{~S}_{3}$. Neutron diffractograms and lithium-NMR spectra reveal its crystal structure to be a cation-disordered variety of the $\mathrm{AgBi}_{3} \mathrm{~S}_{5}$ type (synthetic pavonite; monoclinic, $C 2 / m$ ). Topological analyses and lithium-NMR relaxometry suggest that correlated lithium-ion diffusion with activation energies up to $0.66(2) \mathrm{eV}$ occurs along the channels in $b$ direction including tetrahedral voids. Because of cation disorder, immobile bismuth(III) ions clog these pathways, making $\mathrm{LiBi}_{3} \mathrm{~S}_{5}$ a moderate to poor ionic conductor. The synthesis route reported is nonetheless promising for new lithium bismuth sulfides with, possibly ordered, structure types of the pavonite homologous series.
\end{abstract}

\section{Keywords}

Lithium bismuth sulfide; Crystal structure; Neutron powder diffraction; Topological analysis; Lithium NMR; Lithium diffusion pathways

\section{Introduction}

Semiconducting chalcogenide compounds have been receiving much attention because of their wide range of applications in various fields of science and technology. One of the most

\footnotetext{
${ }^{*}$ Corresponding author. E-mail address: dennis.wiedemann@chem.tu-berlin.de (D. Wiedemann).
} 
promising areas is their use in thermoelectric refrigeration or portable power generation [1]. Various solid solutions of $\mathrm{M}_{2} \mathrm{X}_{3}$ phases $(\mathrm{M}=\mathrm{As}, \mathrm{Sb}, \mathrm{Bi} ; \mathrm{X}=\mathrm{S}, \mathrm{Se}, \mathrm{Te})$, which are excellent for thermoelectric applications near room temperature, have been the most investigated materials during the last half century [2].

In recent years, intense efforts focused on discovering new materials amongst ternary and quaternary alkali-metal bismuth chalcogenides. This class of compounds has proven to be remarkably large and has contributed many complex compositions and structures favorable for high thermoelectric performance [3], e.g., $\mathrm{K}_{2.5} \mathrm{Bi}_{8.5} \mathrm{Se}_{14}$ [4], $\beta-\mathrm{K}_{2} \mathrm{Bi}_{8} \mathrm{Se}_{13}$ [4], $\mathrm{A}_{2} \mathrm{Bi}_{8} \mathrm{Se}_{13}$ $(\mathrm{A}=\mathrm{Rb}, \mathrm{Cs})$ [5], and $\mathrm{CsBi}_{4} \mathrm{Te}_{6}$ [6]. In comparison to selenides and tellurides, most of the alkali-metal bismuth sulfides exhibit wide energy band gaps and strong ionic interactions between the alkali-metal ions and the $\left[\mathrm{Bi}_{x} \mathrm{~S}_{y}\right]^{z-}$ framework, e.g., in $\beta$ - and $\gamma-\mathrm{CsBiS}_{2}$ [7], $\gamma-$ $\mathrm{RbBi}_{3} \mathrm{~S}_{5}$ [8], and $\mathrm{KBi}_{3} \mathrm{~S}_{5}$ [9]. Because of these characteristics, further compounds of this class are sought after. As $\mathrm{KBi}_{3} \mathrm{~S}_{5}$ has the potential to act as a host for ion exchange, Chondroudis and Kanatzidis used a low temperature solid-state route to exchange the potassium ions for a variety of other ions. Reaction of the host material with $\mathrm{RbCl}$, LiI, NaI, or $\left(\mathrm{NH}_{4}\right) \mathrm{I}$ yielded the isostructural compounds $\beta-\mathrm{RbBi}_{3} \mathrm{~S}_{5}, \mathrm{Li}_{0.82} \mathrm{~K}_{0.18} \mathrm{Bi}_{3} \mathrm{~S}_{5}, \mathrm{Na}_{0.66} \mathrm{~K}_{0.33} \mathrm{Bi}_{3} \mathrm{~S}_{5}$, and $\left(\mathrm{NH}_{4}\right) \mathrm{Bi}_{3} \mathrm{~S}_{5}$ [10]. $\mathrm{KBi}_{3} \mathrm{~S}_{5}$ was, however, not completely converted to the corresponding lithium and sodium compound using this route, whereas the synthesis of pure $\left(\mathrm{NH}_{4}\right) \mathrm{Bi}_{3} \mathrm{~S}_{5}$ has been reported to be possible.

In this work, we present the selective synthesis of $\mathrm{LiBi}_{3} \mathrm{~S}_{5}$, a compound that has been announced, but hitherto very poorly characterized. Lazarev et al. assumed its existence on the basis of differential thermal analysis (DTA) and provided a list of the strongest reflections in X-ray diffraction as well as temperature-dependent conductivity measurements [11]. Unfortunately, the lack of experimental and evaluative descriptions makes these pieces of information rather vague and difficult to interpret. So far, lithium bismuth disulfide $\mathrm{LiBiS}_{2}$ ( $\mathrm{NaCl}$ type with statistical cation distribution) had been the only well-known ternary compound in the system $\mathrm{Li}-\mathrm{Bi}-\mathrm{S}$. We describe $\mathrm{LiBi}_{3} \mathrm{~S}_{5}$ as a second member, supplying crystal-structure refinements based on neutron diffraction, nuclear magnetic resonance (NMR) investigations on lithium-ion dynamics, and topological analyses of possible lithiumdiffusion pathways. Since $\mathrm{LiBi}_{3} \mathrm{~S}_{5}$ is expected to show both electronic and ionic conduction, lithium NMR was chosen to selectively [12] probe lithium-ion dynamics in the mixed conductor. 


\section{Materials and Methods}

\subsection{Syntheses}

All reactants have been used in their naturally occurring isotope mixture.

LiBiS $: \mathrm{Li}_{2} \mathrm{CO}_{3}$ and $\mathrm{Bi}_{2} \mathrm{O}_{3}$ powders (molar ratio 1:1) were shaken together and the mixture was thoroughly ground in an agate mortar. It was then heated under $\mathrm{H}_{2} \mathrm{~S}$ flow in an alumina crucible at $600{ }^{\circ} \mathrm{C}$ for $4 \mathrm{~h}$ to give lithium bismuth disulfide as a black powder.

$\boldsymbol{B i}_{2} \boldsymbol{S}_{3}: \mathrm{Bi}_{2} \mathrm{O}_{3}$ was reacted in an alumina crucible under $\mathrm{H}_{2} \mathrm{~S}$ flow at $400{ }^{\circ} \mathrm{C}$ for $4 \mathrm{~h}$ to give dibismuth trisulfide as a black powder.

$\mathbf{L i B i}_{3} \boldsymbol{S}_{5}:$ Samples were prepared via two different routes:

1) $\mathrm{LiBiS}_{2}$ and $\mathrm{Bi}_{2} \mathrm{~S}_{3}$ powders (molar ratio 1:1) were shaken together and the mixture was thoroughly ground in an agate mortar. It was then heated under $\mathrm{H}_{2} \mathrm{~S}$ flow in an alumina crucible at $600{ }^{\circ} \mathrm{C}$ for $4 \mathrm{~h}$ to give lithium tribismuth pentasulfide. Excess sulfur from catalytic decomposition of $\mathrm{H}_{2} \mathrm{~S}$ was removed at $150{ }^{\circ} \mathrm{C}$ in vacuo within $24 \mathrm{~h}$. As the grey-black powders prepared in this way contained small amounts of side phases ( $\mathrm{Bi}_{2} \mathrm{~S}_{3}$ or bismuth), the following route was chosen for further studies.

2) $\mathrm{LiBiS}_{2}$ and $\mathrm{Bi}_{2} \mathrm{~S}_{3}$ powders were dried in vacuo at $150{ }^{\circ} \mathrm{C}$ within $24 \mathrm{~h}$. A mixture of them (molar ration 1:1) was sealed in an evacuated silica-glass ampoule and heated to $600{ }^{\circ} \mathrm{C}$ with a gradient of $25^{\circ} \mathrm{C} / \mathrm{h}$. It was kept at that temperature for $48 \mathrm{~h}$ and then rapidly quenched to ambient temperature. Excess sulfur (from catalytic decomposition of $\mathrm{H}_{2} \mathrm{~S}$ during precursor synthesis) was removed at $150{ }^{\circ} \mathrm{C}$ in vacuo within $24 \mathrm{~h}$ to leave lithium tribismuth pentasulfide as a grey-black powder.

Anal. found: Bi, 79.15; Li, 0.90; S, 20.44. Calc. for $\mathrm{Bi}_{3} \mathrm{LiS}_{5}$ (794.18): Bi, 78.94; $\mathrm{Li}$, 0.87; S, 20.35wt\%. Void of silicon, aluminum (ampoule materials), and oxygen.

\subsection{Chemical Characterization}

The absence of oxygen compounds was verified using a "Leco EF-TC" $300 \mathrm{~N}_{2} / \mathrm{O}_{2}$ analyzer (hot-gas extraction). The sulfur content was determined using a "Thermo Finnigan Flash EA 1112 " analyzer. Determination of the bismuth and sulfur contents as well as checks for the absence of silicon and aluminum were accomplished via X-ray fluorescence (XRF) analysis on a "PANalytical Axios PW4400/24" spectrometer equipped with a rhodium tube and a wavelength-dispersive detector. Lithium determinations were carried out with an "Agilent 7500ce ICPMS” (Agilent Technologies, Waldbronn, Germany). 


\subsection{Crystal Structure Determination}

Neutron diffraction was carried out at the neutron facility FRM II (Maier-Leibnitz Zentrum, Garching b. München) using the high-resolution powder diffractometer SPODI with Ge(551)monochromated radiation $(\lambda=154.831 \mathrm{pm})$ in Debye-Scherrer geometry [13]. The compacted powder sample was mounted in a vanadium cylinder $(d=9 \mathrm{~mm}, h=40 \mathrm{~mm})$ at r.t. and exposed for $12 \mathrm{~h}$. Data were recorded with an array of 80 position-sensitive ${ }^{3} \mathrm{He}$ tubes $\left(2 \theta_{\max }=160^{\circ}\right.$, effective height: $\left.300 \mathrm{~mm}\right)$ and reduced using a variable-height algorithm as implemented in the in-house parser [14], yielding a final range of $0.95^{\circ} \leq 2 \theta \leq 151.90^{\circ}$ with $\Delta(2 \theta)=0.05^{\circ}$. X-ray diffraction was carried out on a "PANalytical X'Pert PRO MPD" diffractometer equipped with a "PIXcel" detector using nickel-filtered $\mathrm{Cu}-K_{\alpha}$ radiation $\left(\lambda_{1}=154.056 \mathrm{pm}, \lambda_{2}=154.439 \mathrm{pm}\right)$ in Bragg-Brentano $(\theta-\theta)$ geometry.

For Rietveld refinements, a known model for $\mathrm{AgBi}_{3} \mathrm{~S}_{5}$ [15] from the Inorganic Crystal Structure Database (ICSD) [16] was imported, adjusted to reflect the actual cell parameters and contents, and refined against net intensities with FULLPROF [17] using the full-matrix least-squares algorithm with fixed elements per cycle. Neutron data were analytically corrected for absorption (cylindrical sample) and stripped of the inclined inset between 0 and $4^{\circ}$. The background was defined manually with 20 (neutrons) or 17 (X-rays) points of refined height. Peak profiles were fitted with a pseudo-Voigt function (Gaussian parameters $U, V$, and $W$; Lorentzian parameter $X$; mixing parameter $\eta$ ). Asymmetry was corrected for using the Bérar-Baldinozzi method with two (neutrons) or four parameters (X-rays) [18]. A scale factor and a zero-shift correction (neutrons) or displacement and transparency corrections (X-rays) were applied.

Same-position and same-ADP constraints were applied to bismuth and lithium ions sharing approximately same positions. The isotropic displacement parameters of $\mathrm{Bi} 4 / \mathrm{Li} 4$ and $\mathrm{Bi} 5 / \mathrm{Li} 5$ were fixed at the average of those of the other ions. All other ions were refined with individual anisotropic (neutrons) or isotropic (X-rays) atomic displacement. All positions included were constrained to be fully occupied. As the occupation of Bi3 refined to a value only insignificantly lower than 0.5 for neutron data, it was fixed at this value. Furthermore, the sum of bismuth occupations was found to be very close to the one given by the chemical composition and was thus restrained to equal it. Tables 1 and S1 list further experimental details, Fig. 1 and S1 show the neutron and X-ray diffractogram, respectively. 
Table 1. Details of neutron powder diffraction at $\mathrm{LiBi}_{3} \mathrm{~S}_{5}$.

\begin{tabular}{cc}
\hline Sum formula & $\mathrm{LiBi}_{3} \mathrm{~S}_{5}$ \\
\hline$T / \mathrm{K}$ & 298 \\
Crystal system & monoclinic \\
Space group & $C 2 / m$ \\
$\lambda / \mathrm{pm}$ & 154.831 \\
$Z$ & 4 \\
$M / \mathrm{g} \mathrm{mol}^{-1}$ & 794.2 \\
$a / \mathrm{pm}$ & $1310.79(2)$ \\
$b / \mathrm{pm}$ & $400.070(7)$ \\
$c / \mathrm{pm}$ & $1650.85(3)$ \\
$\beta /{ }^{\circ}$ & $94.0723(12)$ \\
$V / 10^{6} \mathrm{pm}^{3}$ & $863.53(3)$ \\
$\rho_{\text {calc }} / \mathrm{g} \mathrm{cm}{ }^{3}$ & 6.109 \\
$\mu / \mathrm{mm}^{-1}$ & 0.0297 \\
$R_{\mathrm{p}}$ & 0.0160 \\
$R_{\mathrm{wp}}$ & 0.0190 \\
$R_{\text {exp }}$ & 0.0125 \\
$R_{\mathrm{B}}$ & 0.0367 \\
$R_{\mathrm{F}}$ & 0.0216 \\
$S$ & 1.52 \\
\hline
\end{tabular}

Structure graphics were produced using DiAmOND 3.2 [19]. Analysis of the Hirshfeld surface under exclusion of lithium ions was performed using CRYSTALEXPLORER 3.1 [20]. For Voronoi-Dirichlet partitioning analysis, TOPOSPRO 5.1 [21] was employed in a standard procedure: After detection, too small elementary voids (spherical-domain radius $R_{\mathrm{sd}}<158 \mathrm{pm}$ for lithium ions in sulfide environments [22]) and channels (adjacency radius $R_{\mathrm{ad}}<219 \mathrm{pm}$, $90 \%$ of sum of ionic radii [23]) as well as those not only determined by sulfide ions (solid angle of interaction with bismuth ions $\Omega>10 \% \times 4 \pi$ ) were discarded [24].

Further details of the crystal structure investigations may be obtained from FIZ Karlsruhe, 76344 Eggenstein-Leopoldshafen, Germany (fax: +49 7247 808-666; e-mail: crysdata@fizkarlsruhe.de), on quoting the deposition numbers CSD-430770 (neutrons) and -430769 (Xrays).

\subsection{Lithium NMR}


For the ${ }^{7} \mathrm{Li}-\mathrm{NMR}$ measurements under static, i.e., non-rotating conditions, the $\mathrm{LiBi}_{3} \mathrm{~S}_{5}$ powder prepared was fire-sealed under vacuum in DURAN ${ }^{\circledR}$ glass ampoules $(c a .4 \mathrm{~cm}$ in length and $0.5 \mathrm{~cm}$ in diameter) to permanently protect the sulfide from any moisture or air.

${ }^{7}$ Li-NMR measurements were performed using a "Bruker Avance III" spectrometer, which was connected to a shimmed cryomagnet with a nominal external magnetic field of $B_{0}=7.04 \mathrm{~T}$, which corresponds to a ${ }^{7} \mathrm{Li}$ resonance frequency of $\omega_{0} / 2 \pi=116.4 \mathrm{MHz}$. A ceramic high-temperature NMR probe (Bruker BioSpin) was employed that allows $\pi / 2$ pulse lengths of $c a$. 6 to $7.5 \mu \mathrm{s}$ at $200 \mathrm{~W}$. The exact $\pi / 2$ pulse length depends on temperature. The temperature in the sample chamber (223 to $573 \mathrm{~K}$ ) was adjusted via a "Eurotherm" controller and a stream of freshly evaporated dinitrogen. ${ }^{7} \mathrm{Li}-\mathrm{NMR}$ spectra and ${ }^{7} \mathrm{Li}$ spin-lattice relaxation (SLR) rates $\left(1 / T_{1}=R_{1}\right)$ in the laboratory frame of reference were recorded with the wellknown saturation recovery pulse sequence. In our case, this sequence consists of ten $\pi / 2$ pulses destroying any longitudinal magnetization $M$ followed by an evolution period allowing for the recovery of $M\left(t_{\mathrm{d}}\right): 10 \times \pi / 2-t_{\mathrm{d}}-\pi / 2$-acquisition (acq). The last pulse is used for detection of the free induction decay (FID). In addition, we used spin-lock NMR relaxometry to probe slower ion dynamics. ${ }^{7} \mathrm{Li}$ SLR rates in the so-called rotating frame of reference $\left(1 / T_{1 \rho}=R_{1 \rho}\right)$ were recorded with the following pulse sequence: $\pi / 2_{X^{\prime}}$-spin-locking pulse $\left(t_{\text {lock }}\right)$ - acq. The first pulse flips the equilibrium magnetization $M$ into the $(x y)^{\prime}$-plane; the spin-lock pulse, directly following the pulse to prepare the spin-system, is used to hold the transversal component of $M$. During the locking pulse, which is generated via the $B_{1}$ field characterized by $\omega_{1} / 2 \pi$ in the kilohertz range, $M$ has to adopt a new equilibrium value that is much smaller than that corresponding to $B_{0}$. Hence, a transversal decay of $M\left(t_{\text {lock }}\right)$ is monitored that is influenced by lithium-ion diffusion at sufficiently high $T$. Here, we used a spin-lock frequency of $c a .20 \mathrm{kHz}$. Between the acquisitions of each spin-lock FID, a recycle delay of at least $5 T_{1}$ was applied.

To gather information on local magnetic structures around the lithium nuclei, ${ }^{6} \mathrm{Li}$ magic-angle spinning (MAS) NMR was used. The corresponding spectra were recorded at $296 \mathrm{~K}$ using a "Bruker Avance III" $500 \mathrm{MHz}$ spectrometer, which was connected to a shimmed $11.7 \mathrm{~T}$ cryomagnet, resulting in a nominal ${ }^{6} \mathrm{Li}$ resonance frequency of $73.6 \mathrm{MHz}$. Spinning was carried out using 2.5-mm rotors (Bruker) that are able to rotate the samples at speeds as high as $30 \mathrm{kHz}$.

\section{Results and Discussion}




\subsection{Structure Determination}

We started structure determination by recording and interpreting an X-ray diffractogram (see Fig. S1). A first inspection showed it to be roughly reconcilable with the interplanar spacings and corresponding intensities tabulated before [15], so that we assume to have the same compound in our hands. The comparison to X-ray diffractograms of other known compounds collected in the ICSD suggested that $\mathrm{LiBi}_{3} \mathrm{~S}_{5}$ is of the $\mathrm{AgBi}_{3} \mathrm{~S}_{5}$ (synthetic pavonite) type. Subsequent Rietveld refinement using a model of this structure type and inspection of difference electron-density maps revealed ample occupation of the positions originally attributed to silver(I) ions by bismuth(III) ions (see Tables S1-S2). A free refinement of bismuth occupations led to an empirical formula of approximately $\mathrm{Bi}_{2.9} \mathrm{~S}_{5}$, so that we restrained the bismuth content to 3.0 -also in accordance with chemical analysis. No significant residual electron-density maxima were found after this procedure.

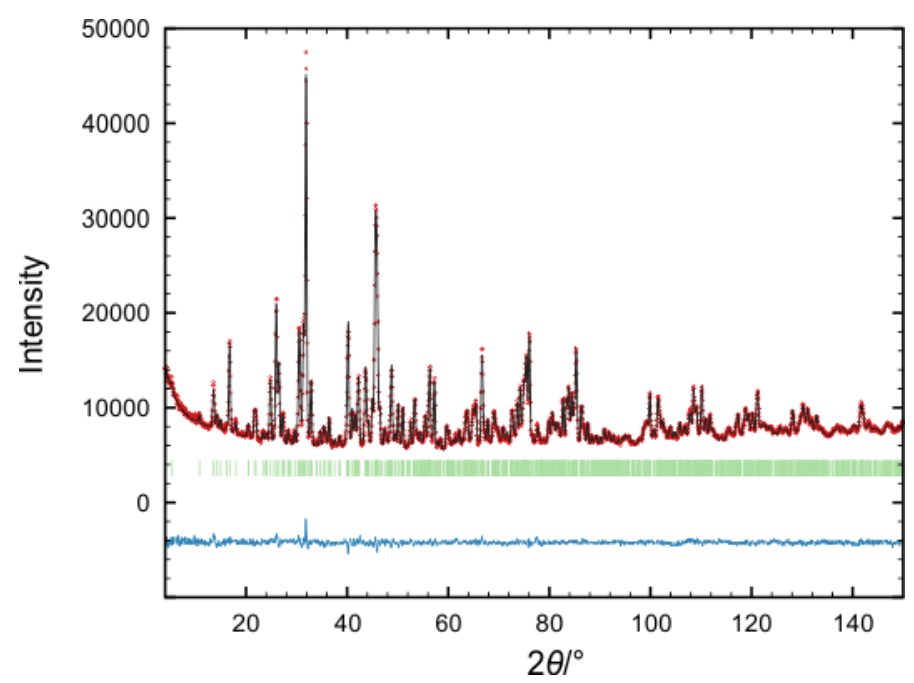

Fig. 1. Neutron powder diffractogram of $\mathrm{LiBi}_{3} \mathrm{~S}_{5}$ with the results of the Rietveld refinement (black: measured, red: calculated intensities, green: Bragg positions, blue: intensity difference).

Table 2. Atomic coordinates and site occupation factors (s.o.f.) for $\mathrm{LiBi}_{3} \mathrm{~S}_{5}$ at ambient temperature as derived from neutron powder diffraction.

\begin{tabular}{cccccc}
\hline Atom & Wyckoff site & $x$ & $y$ & $z$ & s.o.f. \\
\hline Bi1 & $4 i$ & $0.23805(16)$ & $1 / 2$ & $0.11122(10)$ & $0.821(3)$ \\
Li1 & $4 i$ & $0.23805(16)$ & $1 / 2$ & $0.11122(10)$ & $0.179(3)$ \\
Bi2 & $4 i$ & $0.47179(14)$ & 0 & $0.21890(10)$ & $0.876(3)$ \\
Li2 & $4 i$ & $0.47179(14)$ & 0 & $0.21890(10)$ & $0.124(3)$ \\
Bi3 & $4 i$ & $0.21539(12)$ & 0 & $0.39076(8)$ & 1 \\
Bi4 & $2 a$ & 0 & 0 & 0 & $0.450(3)$ \\
Li4 & $2 a$ & 0 & 0 & 0 & $0.550(3)$ \\
Bi5 & $2 d$ & 0 & $1 / 2$ & $1 / 2$ & $0.156(3)$
\end{tabular}




\begin{tabular}{cccccc} 
Li5 & $2 d$ & 0 & $1 / 2$ & $1 / 2$ & $0.844(3)$ \\
S1 & $4 i$ & $0.3716(4)$ & 0 & $0.0535(3)$ & 1 \\
S2 & $4 i$ & $0.1069(4)$ & 0 & $0.1534(3)$ & 1 \\
S3 & $4 i$ & $0.3411(3)$ & $1 / 2$ & $0.2580(3)$ & 1 \\
S4 & $4 i$ & $0.0706(3)$ & $1 / 2$ & $0.3631(3)$ & 1 \\
S5 & $4 i$ & $0.3536(3)$ & $1 / 2$ & $0.4656(2)$ & 1 \\
\hline
\end{tabular}

Table 3. Displacement parameters (in $10^{4} \mathrm{pm}^{2}$ ) for $\mathrm{LiBi}_{3} \mathrm{~S}_{5}$ at ambient temperature as derived from neutron powder diffraction.

\begin{tabular}{ccccccccc}
\hline Atom & $U_{\text {iso }}$ & $U_{\text {eq }}$ & $U_{11}$ & $U_{22}$ & $U_{33}$ & $U_{12}$ & $U_{13}$ & $U_{23}$ \\
\hline Bi1 & - & $0.0162(11)$ & $0.0110(10)$ & $0.0123(11)$ & $0.0254(12)$ & 0 & $0.0011(9)$ & 0 \\
Li1 & - & $0.0162(11)$ & $0.0110(10)$ & $0.0123(11)$ & $0.0254(12)$ & 0 & $0.0011(9)$ & 0 \\
Bi2 & - & $0.0190(11)$ & $0.0192(10)$ & $0.0178(10)$ & $0.0200(12)$ & 0 & $-0.0030(10)$ & 0 \\
Li2 & - & $0.0190(11)$ & $0.0192(10)$ & $0.0178(10)$ & $0.0200(12)$ & 0 & $-0.0030(10)$ & 0 \\
Bi3 & - & $0.0254(9)$ & $0.0309(9)$ & $0.0224(8)$ & $0.0230(10)$ & 0 & $0.0068(7)$ & 0 \\
\hline Bi4 & 0.01825 & - & - & - & - & - & - & - \\
Li4 & 0.01825 & - & - & - & - & - & - & - \\
Bi5 & 0.01825 & - & - & - & - & - & - & - \\
Li5 & 0.01825 & - & - & - & - & - & - & - \\
\hline S1 & - & $0.018(2)$ & $0.034(3)$ & $0.0101(19)$ & $0.010(2)$ & 0 & $0.009(2)$ & 0 \\
S2 & - & $0.020(2)$ & $0.011(2)$ & $0.023(2)$ & $0.027(3)$ & 0 & $0.007(2)$ & 0 \\
S3 & - & $0.016(2)$ & $0.012(2)$ & $0.013(2)$ & $0.024(2)$ & 0 & $0.011(2)$ & 0 \\
S4 & - & $0.016(2)$ & $0.020(2)$ & $0.0122(20)$ & $0.017(2)$ & 0 & $-0.0100(19)$ & 0 \\
S5 & - & $0.015(2)$ & $0.019(2)$ & $0.0109(19)$ & $0.017(2)$ & 0 & $-0.0045(17)$ & 0 \\
\hline
\end{tabular}

As lithium ions are notoriously weak X-ray scatterers, we have performed powder neutron diffraction to unambiguously locate them in the crystal structure. Results of the Rietveld refinement are shown in Fig. 1 and summarized in Tables 1-3. Starting with the model acquired from X-ray data, difference maps of scattering-length density revealed occupation of most cation positions (especially Bi4 and Bi5) with lithium ions. As free refinement led to site occupation factors (s.o.f.) greater than one, all positions were constrained to be fully occupied either by bismuth or lithium ions. The s.o.f. of $\mathrm{Bi} 3$ was found to be insignificantly smaller than unity and thus constrained to reflect full bismuth occupation. The data then allowed for refinement of all positions, except for $\mathrm{Bi} 4 / \mathrm{Li} 4$ and $\mathrm{Bi} / \mathrm{Li} 5$, with anisotropic displacement parameters (ADPs). Even in the isotropic case - as also noticed in the fitting to X-ray data before-, negative or huge displacement parameters resulted for $\mathrm{Bi} 4 / \mathrm{Li} 4$ and $\mathrm{Bi} 5 / \mathrm{Li} 5$, respectively. Neither the shift of these ions to general positions nor the permission of 
anharmonic contributions to displacement led to physically sensible models and stable refinements at the same time. Consequently, we fixed their $U_{\text {iso }}$ at the average of all other $U_{\text {eq. }}$. Notably, these complications occur at the only two positions with (a) considerable lithium occupation and (b) the highest site symmetry possible in this space group. In our opinion, the misfit between lithium(I) and bismuth(III) may well lead to a disorder over these positions that is unresolvable because of severe reflection overlap. This problem is especially prominent in the high-angle regime, thus leading to difficulties evaluating displacement parameters. The final model led to an empirical formula very close to $\mathrm{Bi}_{3} \mathrm{LiS}_{5}$; occupation sums were then restrained to equal it.

\subsection{Structure Description}

$\mathrm{LiBi}_{3} \mathrm{~S}_{5}$ crystallizes in the $\mathrm{AgBi}_{3} \mathrm{~S}_{5}$ type, the eponym of which is a member $(N=5)$ of the socalled pavonite homologous series with the general formula $\left[\mathrm{Bi}_{2} \mathrm{~S}_{3}\right]_{2} \cdot\left[\mathrm{AgBiS}_{2}\right]_{(N-1) / 2}[15]$. The different members of the pavonite homologues series are usually denoted by the symbol ${ }^{N} \mathrm{P}$, where $N$ is the number of the octahedra per diagonal octahedral chain of the thicker slabs in the structure (see Fig. 2).

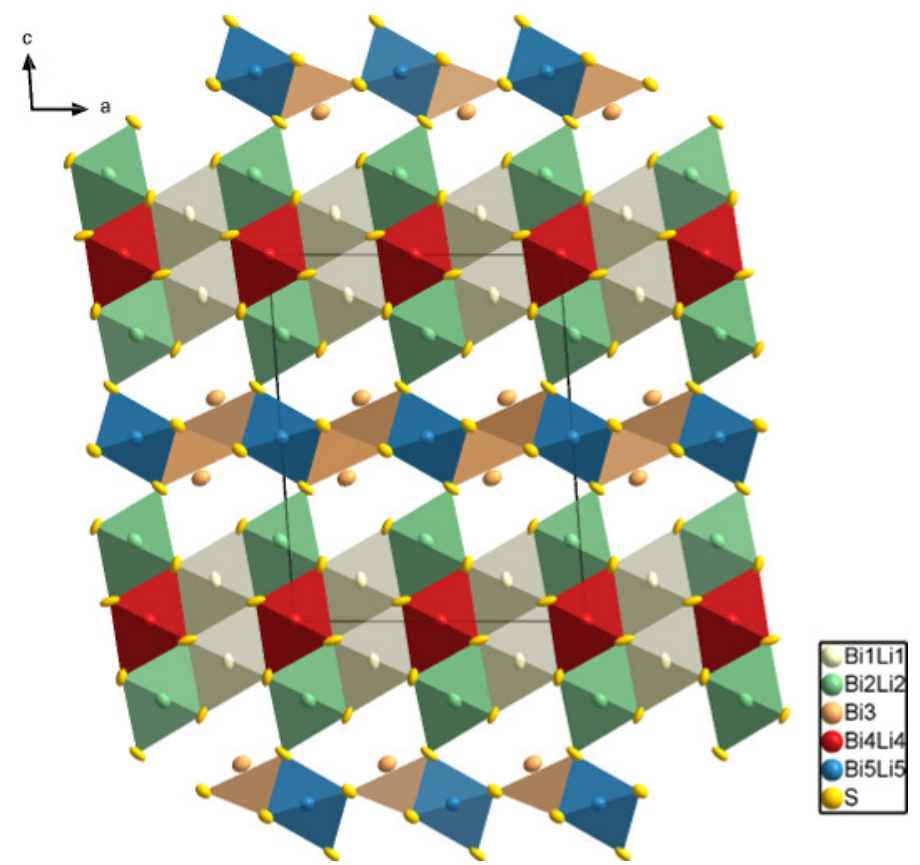

Fig. 2. Unit cell of $\mathrm{LiBi}_{3} \mathrm{~S}_{5}$ and polyhedral representation of the crystal structure.

Four of the bismuth and all of the lithium ions present in the crystal structure are octahedrally coordinated by six sulfide ions. The remaining Bi3 is coordinated by five close sulfide ions in the fashion of a square pyramid. This position is not accidentally unoccupied by lithium, as a 
square pyramidal coordination would be unfavorable. The crystal structure of $\mathrm{LiBi}_{3} \mathrm{~S}_{5}$ is composed of two types of alternating slabs parallel to (001), which can be described as assembly of blocks excised from a distorted NaCl-type structure. The thinner slabs are composed of single $\mathrm{MS}_{6}$ octahedra $\left(\mathrm{M}=\mathrm{Bi} 5\right.$, Li5) sandwiched by two square $(\mathrm{Bi} 3) \mathrm{S}_{5}$ pyramids along [100]. In the thicker slabs (thickness varying with $N$ in the ${ }^{N}$ P-pavonite series), the arrangement of the sulfide ions deviates only slightly from a cubic close packing. In our case, they consist of five $\mathrm{MS}_{6}$ octahedra $(\mathrm{M}=\mathrm{Bi} 1, \mathrm{Li} 1, \mathrm{Bi} 2, \mathrm{Li} 2, \mathrm{Bi} 4, \mathrm{Li} 4)$ per diagonal chain. The two types of slabs are connected via vertices at S4, which is part of the polyhedra around $\mathrm{Bi} 2 / \mathrm{Li} 2$, $\mathrm{Bi} 3$, and $\mathrm{Bi} 5 / \mathrm{Li} 5$.

The individual and average bond lengths, volumes, and continuous shape measure for all coordination polyhedra are listed in Table 4. The latter quantifies the minimal distance movement that the ions would have to undergo to be transformed into an ideal shape (e.g., an octahedron or a square pyramid) [25]. All average bond lengths in $\mathrm{LiBi}_{3} \mathrm{~S}_{5}$ are close to the reported values for $\mathrm{AgBi}_{3} \mathrm{~S}_{5}$ [15]. It is noteworthy that $\mathrm{Bi} 3$ binds to only five sulfide ions, thus forming a distorted square pyramid, and interacts with two additional anions in the thicker slab at a long distance of 346.9(4) pm. If these were included into the coordination polyhedron, it would be considered an augmented triangular prism. Amongst the positions partially occupied by lithium ions, Bi5/Li5 holds a somewhat special place: the smallest bond lengths in the structure (only ca. $250 \mathrm{pm}$ ) are found here and lead to an average, which is by ca. $10 \mathrm{pm}$ smaller than those for the other cation positions. This causes a way smaller and much more strongly distorted coordination octahedron, making it particularly unfavorable for hosting bismuth(III) $\left(r_{\mathrm{eff}}=103 \mathrm{pm}\right)$ instead of lithium(I) ions $\left(r_{\mathrm{eff}}=76 \mathrm{pm}\right.$ [23]). Disorder between these two species itself is well known, e.g., in the sulfidic $\mathrm{LiBiS}_{2}$ [26] or in various oxidic materials [27, 28].

Table 4. Bond lengths in $\mathrm{LiBi}_{3} \mathrm{~S}_{5}$ at ambient temperature as derived from neutron powder diffraction.

\begin{tabular}{|c|c|c|c|c|c|}
\hline Atom1 & Atom2 & Count & $d / \mathrm{pm}$ & $V_{\mathrm{cp}} / 10^{6} \mathrm{pm}^{3 a}$ & $S(\mathrm{cp})^{b}$ \\
\hline \multirow[t]{5}{*}{ Bi1/Li1 } & S3 & $1 \times$ & $268.9(5)$ & & \\
\hline & S2 & $2 \times$ & $275.9(4)$ & & \\
\hline & S1 & $2 \times$ & $286.5(4)$ & & \\
\hline & $\mathrm{S} 1$ & $1 \times$ & $298.4(5)$ & & \\
\hline & \multicolumn{2}{|c|}{ average } & $282(11)$ & 67.75 & 0.05 \\
\hline \multirow[t]{2}{*}{$\mathrm{Bi} 2 / \mathrm{Li} 2$} & S4 & $1 \times$ & $262.8(5)$ & & \\
\hline & S3 & $2 \times$ & $274.0(3)$ & & \\
\hline
\end{tabular}




\begin{tabular}{|c|c|c|c|c|c|}
\hline & $\mathrm{S} 2$ & $2 \times$ & $292.9(4)$ & & \\
\hline & $\mathrm{S} 1$ & $1 \times$ & $294.5(5)$ & & \\
\hline & \multicolumn{2}{|c|}{ average } & $282(14)$ & 62.28 & 0.11 \\
\hline \multirow[t]{4}{*}{$\mathrm{Bi} 3$} & S5 & $1 \times$ & $259.7(4)$ & & \\
\hline & $\mathrm{S} 4$ & $2 \times$ & $277.3(3)$ & & \\
\hline & S5 & $2 \times$ & $291.4(3)$ & & \\
\hline & \multicolumn{2}{|c|}{ average } & $279(14)$ & 79.87 & 0.87 \\
\hline \multirow[t]{3}{*}{$\mathrm{Bi} 4 / \mathrm{Li} 4$} & $\mathrm{~S} 1$ & $4 \times$ & $279.7(4)$ & & \\
\hline & $\mathrm{S} 2$ & $2 \times$ & $280.6(5)$ & & \\
\hline & \multicolumn{2}{|c|}{ average } & $280.0(5)$ & 52.16 & 0.01 \\
\hline \multirow[t]{3}{*}{$\mathrm{Bi5} / \mathrm{Li} 5$} & S4 & $2 \times$ & $250.2(5)$ & & \\
\hline & S5 & $4 \times$ & $280.2(3)$ & & \\
\hline & \multicolumn{2}{|c|}{ average } & $270(16)$ & 34.62 & 0.67 \\
\hline
\end{tabular}

\footnotetext{
${ }^{a}$ Volume of the coordination polyhedron (calculated with TOPOSPRO 5.1 [21]). ${ }^{b}$ Continuous shape measure for the idealized coordination polyhedron (square pyramid for Bi3, octahedron for all others; calculated on CSM website [29]).
}

\subsection{Topological Analysis}

Even though $\mathrm{LiBi}_{3} \mathrm{~S}_{5}$ will be shown to be an, at best, moderate lithium-ion conductor (vide infra), we were interested in the migration paths that are generally possible in pavonite-like materials. For an experimental mapping of lithium diffusion pathways in crystalline solids, neutron diffraction at - preferably multiple-high temperatures is the method of choice $[30,31]$. In the present case, however, effective evaluation of powder data would be severely hampered by cation disorder and low symmetry. To gain insight into probable migration paths nonetheless, we have used two topological methods only requiring the solid-state structure (and tabulated empirical parameters) as input: the Hirshfeld-surface analysis (HSA) and the Voronoi-Dirichlet partitioning (VDP) of the $\mathrm{Bi}_{3} \mathrm{~S}_{5}{ }^{-}$void structure, which have been used successfully in studies on battery materials and fast ion conductors before [29, 32]. Note that the conclusions drawn from the room temperature structure are transferable to high temperature only if no phase transformation or significant thermal dilation of voids takes place. A prerequisite for lithium-ion diffusion is the availability of vacancies or accessible voids (i.e., space to induce Frenkel defects) in the crystal structure. As the former is not the case in stoichiometric $\mathrm{LiBi}_{3} \mathrm{~S}_{5}$, the latter have to be shown to be present.

For the HSA of crystal voids, one is restricted to ordered models. We have thus chosen three cases: a stoichiometric model $(\mathrm{Bi} 1-\mathrm{Bi} 3, \mathrm{Li} 4, \mathrm{Li} 5)$ representing a probable configuration, an 
all-bismuth model (Bi1-Bi5) as worst case (i.e., bulkiest framework), and a defective model (Bi1-Bi3) to investigate accessibility to moving lithium ions. In spite of its quite spacious appearance, the stoichiometric model contains only small voids with a distorted tetrahedral, anionic environment (S3, S4, S4', S5) at the junction of the slabs. Their isosurfaces connect to very narrow channels along [010] at a value of 0.0045 a.u., indicating an unlikely migration path (see Fig. 3a). In the all-bismuth model, the voids stay isolated up to a high isovalue of 0.006 a.u., albeit being accessible from the positions of Li2 and Li5 (see Fig. 3b). The presence of bismuth ions effectively blocks all paths. The defective model shows the largest voids at the vacancies. These voids connect to ample channels along [010] at isovalues of 0.0045 a.u./0.0035 a.u. and above for the deletion of Li4/Li5, respectively (see Fig. 3c). This means that two crystallographically inequivalent, isolated 1D migration pathways along direction $b$ may exist. The less preferable one (for reasons of size) includes Li4, the favored one includes Li5. Any of them would be clogged by bismuth ions Bi4 or Bi5. (In an additional experiment, we heated $\mathrm{LiBi}_{3} \mathrm{~S}_{5}$ to $600{ }^{\circ} \mathrm{C}$ and slowly cooled down to $130{ }^{\circ} \mathrm{C}$ with $0.5^{\circ} \mathrm{C} / \mathrm{h}$. As evidenced by X-ray diffractograms, this did not lead to cation ordering,).

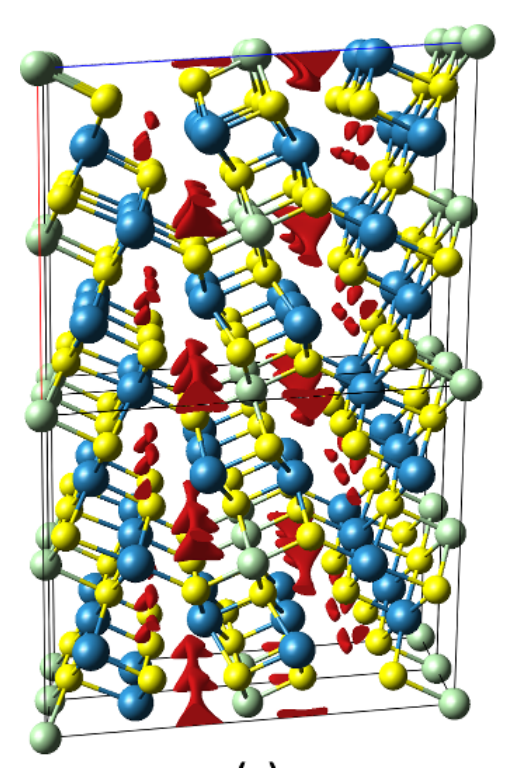

(a)

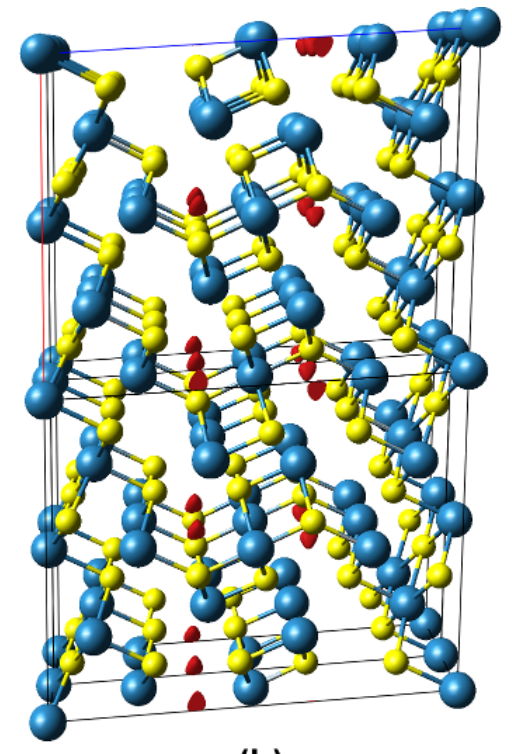

(b)

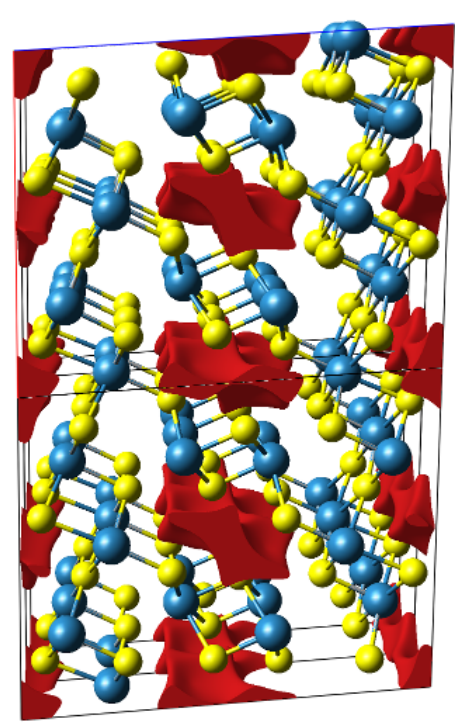

(c)

Fig. 3. Details of $\mathrm{LiBi}_{3} \mathrm{~S}_{5}$ framework models with void surfaces at 0.0045 a.u. (blue: bismuth ions, green: lithium ions, yellow: sulfide ions, red: void surfaces; ions with arbitrary radii, unit cell in black, view approximately along b). (a) Stoichiometric model, (b) all-bismuth model, (c) defective model.

The VDP approach offers further insight, as it includes more detailed information about the size of voids, of the migrating ions, and chemical environment of the pathway. Taking into account the results of the HSA, we have chosen the stoichiometric model with bismuth ions $\mathrm{Bi} 1, \mathrm{Bi} 2, \mathrm{Bi} 3$ and lithium ions Li4 and Li5 for this analysis of a best-case scenario. Of the 34 
major elementary voids found, 14 were large and regular enough for lithium ions. Of these, five were only determined by sulfide ions and thus significant (fit to host a cation), including the abovementioned tetrahedral void and the position of Li4. Elimination of insignificant (too small) elementary channels between those five left the void at Li4 isolated and the tetrahedral position connected to only one elementary void. Thus, they may host interstitial lithium ions, but are not part of the conduction pattern, which is formed by a single migration channel consisting of four elementary voids (see Fig. 4). One (ZA1) is in proximity of the tetrahedral void's center. The two remainders are very close to the position of Li5 and, by symmetry equivalence, form a four-membered ring around it. This may be the reason for a disorder causing the problems that were experienced during refinement of the displacement parameters of Li5/Bi5.

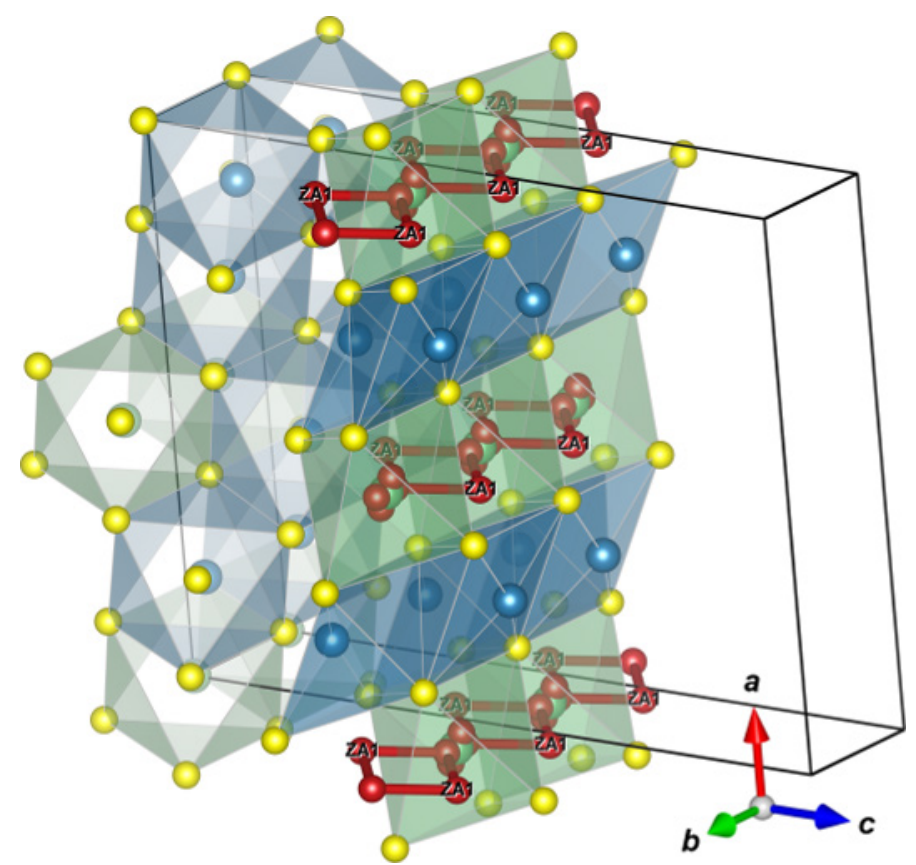

Fig. 4. Detail of ordered model of $\mathrm{LiBi}_{3} \mathrm{~S}_{5}$ with migration channel (blue: bismuth ions, green: lithium ions, yellow: sulfide ions, red: elementary voids and channels; ions with arbitrary radii, unit cell in black).

\subsection{Lithium-NMR Spectra}

To collect information on local magnetic as well as electric structures in $\mathrm{LiB}_{3} \mathrm{~S}_{5}$, we recorded both ${ }^{6} \mathrm{Li}$ - and ${ }^{7} \mathrm{Li}-\mathrm{NMR}$ spectra. High-resolution lithium spectra are usually recorded by taking advantage of lithium-6 (7.5\% natural abundance); this practice is because of the much lower quadrupole moment $q\left({ }^{6} \mathrm{Li}\right)$ (spin quantum number $I=1$ ) as compared to lithium-7 with $I=3 / 2: q\left({ }^{6} \mathrm{Li}\right) / q\left({ }^{7} \mathrm{Li}\right)=1 / 50$. Considering diamagnetic compounds, this circumstance reduces second-order quadrupole broadening being responsible for the low resolution of the 
corresponding ${ }^{7} \mathrm{Li}$ MAS NMR spectra. In the present case, the ${ }^{6} \mathrm{Li}$ MAS NMR spectrum was acquired at a spinning speed of $30 \mathrm{kHz}$ (see Fig. 5a). The total signal is composed of at least two overlapping NMR lines representing the chemically and magnetically inequivalent lithium sites in the sulfide. Large paramagnetic shifts are clearly absent. When referenced to aqueous $\mathrm{LiCl}\left(c=1 \mathrm{~mol} \cdot \mathrm{L}^{-1}\right)$, the resonances appear at $+0.27 \mathrm{ppm}$ and $-1.30 \mathrm{ppm}$, respectively. Because of very similar chemical shifts, it turned out to be rather difficult to resolve all four different lithium environments as deduced from neutron-diffraction data (see above).

a)

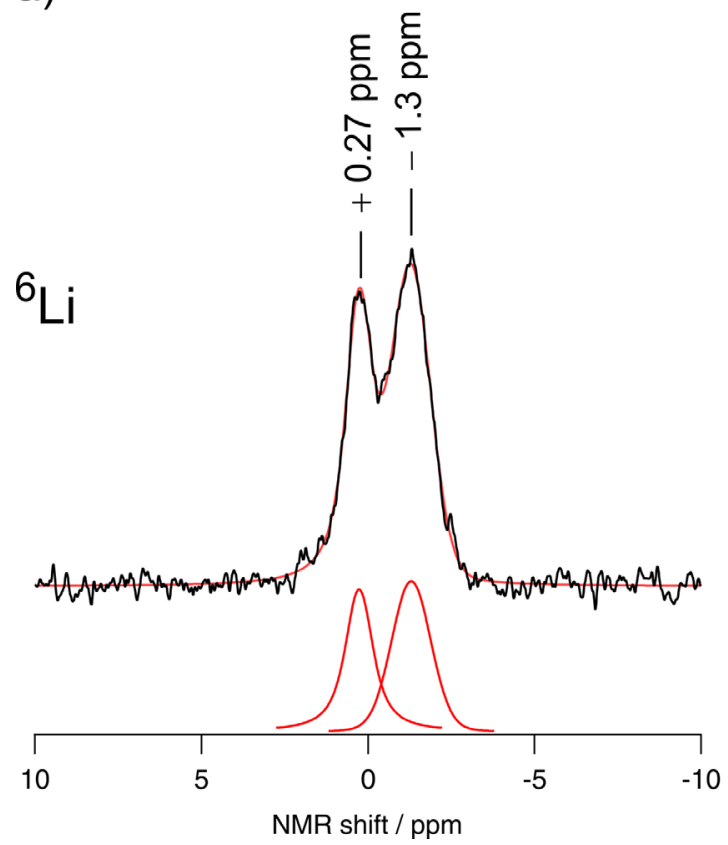

b)

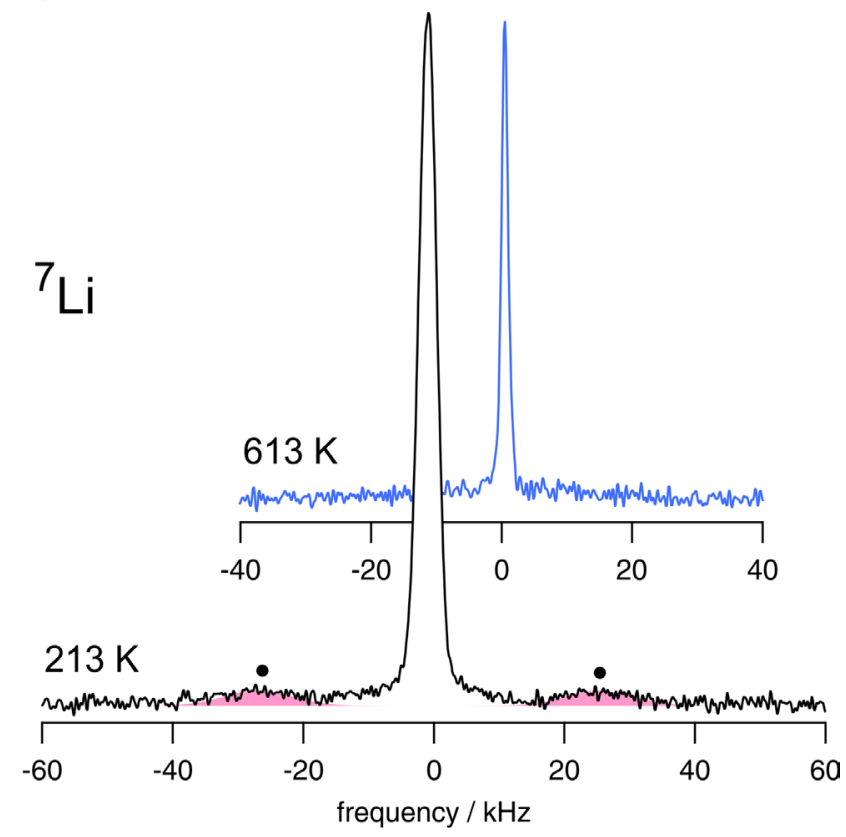

Fig. 5. (a) ${ }^{6} \mathrm{Li}$ MAS spectrum of $\mathrm{LiBi}_{3} \mathrm{~S}_{5}$ recorded with a single-pulse experiment. The $90^{\circ}$ pulse length was $3.33 \mu \mathrm{s}$. The rotation frequency was set to $30 \mathrm{kHz}$. The lithium signal is referenced to aqueous $\mathrm{LiCl}\left(c=1 \mathrm{~mol} \cdot \mathrm{L}^{-1}\right)$. (b) Static ${ }^{7} \mathrm{Li}$-NMR spectra of $\mathrm{LiB}_{3} \mathrm{~S}_{5}$ recorded at $213 \mathrm{~K}$ and $613 \mathrm{~K}$. The black circles mark the $90^{\circ}$ singularities of the quadrupole powder pattern.

If analyzed using two Voigt functions (see Fig. 5a), the area ratio of the two lines is ca. 1:0.9. Most likely, the line at lower chemical shift includes the lithium ions Li5 in the smaller octahedral voids (Wyckoff position: $2 d$ ). The smaller the octahedra, the better the shielding and the larger the up-field shift. The ions residing in larger voids might be characterized by larger chemical shifts.

In general, first insights on lithium-ion dynamics can be deduced from variable-temperature NMR line-shape measurements [33]. The static ${ }^{7} \mathrm{Li}-\mathrm{NMR}$ spectrum of $\mathrm{LiBi}_{3} \mathrm{~S}_{5}$ is composed of a single, Lorentzian-shaped central line (see Fig. 5b) with widths (full width at half maximum, 
fwhm) ranging from $3.1 \mathrm{kHz}$ at $213 \mathrm{~K}$ down to $1.2 \mathrm{kHz}$ at $613 \mathrm{~K}$. While dipole-dipole interactions govern the line width at low $T$, lithium-ion self-diffusion (i.e., exchange of the ions among the magnetically distinct crystallographic sites) increasingly averages magnetic dipolar interactions. Consequently, the line narrows. Plotting the width as a function of $T$ yields the so-called motional narrowing $(\mathrm{MN})$ curve as shown in the inset of Fig. 6. Line narrowing sets in at $c a .290 \mathrm{~K}$ and is pronounced with increasing temperature. Full narrowing, however, is not reached within the temperature range covered. Interestingly, motional narrowing spans a rather large $T$ regime. This behavior indicates a relatively broad distribution of lithium jump rates.

By evaluating the narrowing curve, a mean lithium-ion jump rate $\tau_{\text {MN }}^{-1}$ can be roughly estimated from the inflection point located at $c a$. $500 \mathrm{~K}$. At this temperature, $\tau^{-1}{ }_{\mathrm{MN}} \approx 2 \pi \times v_{\mathrm{rl}}$ holds ( $v_{\mathrm{r}}$ : rigid-lattice line width, i.e., the width at sufficiently low $T$ ) [34]. Here, we obtain jump rates in the order of $\tau_{\mathrm{MN}}^{-1} \approx 2 \times 10^{4} \mathrm{~s}^{-1}$. Such a value points to slow ion diffusion in channel-structured $\mathrm{LiBi}_{3} \mathrm{~S}_{5}$.

As can be seen in Fig. 5b, a shallow quadrupole powder-pattern (two humps next to the central line, each one marked by a circle) shows up at sufficiently low temperature. The humps represent the $90^{\circ}$ singularities of the powder pattern. The spectral separation of $\Delta v_{\mathrm{q}} \approx 50 \mathrm{kHz}$ points to a mean quadrupole coupling constant in the order of $100 \mathrm{kHz}$. Besides magnetic dipolar interactions, also electric quadrupolar interactions are expected to be influenced by rapid lithium diffusion [35]. Indeed, the quadrupole intensities vanish at $T \geq 613 \mathrm{~K}$, meaning that, at this temperature, $\tau^{-1}$ is expected to exceed $\Delta v_{\mathrm{q}}$ by many times.

\subsection{Diffusion-Induced Relaxation Rates}

In order to quantify lithium diffusion in terms of activation energies, ${ }^{7} \mathrm{Li}$ SLR NMR measurements were performed in both the laboratory and rotating frame of reference, i.e., at frequencies of $\omega_{0} / 2 \pi=116.4 \mathrm{MHz}$ and $20 \mathrm{kHz}$ [36,37,38,39]. The corresponding rates $R_{1}$ and $R_{1 \rho}$ were obtained by parametrizing the resulting magnetization transients, $M_{\mathrm{z}}\left(t_{\mathrm{d}}\right)$ and $M_{\mathrm{\rho}}\left(t_{\text {lock }}\right)$, by means of stretched exponentials of the form $M_{\mathrm{z}}\left(t_{\mathrm{d}}\right) \propto 1-\exp \left[-\left(t_{\mathrm{d}} / T_{1}\right)^{\gamma^{\prime}}\right]$ and $M_{\rho}\left(t_{\text {lock }}\right) \propto \exp \left[-\left(t_{\text {lock }} / T_{1 \rho}\right)^{\gamma}\right]$. As an example, the stretching exponent $\gamma$ varies only slightly with temperature (0.57-0.71). In Fig. S2, some selected $R_{1 \rho}$ transients are shown to illustrate the quality of the curves recorded at a locking frequency of $20 \mathrm{kHz}$. Depending on temperature 
and stretching, most of the transients could be monitored over a dynamic range of two to three orders of magnitude.

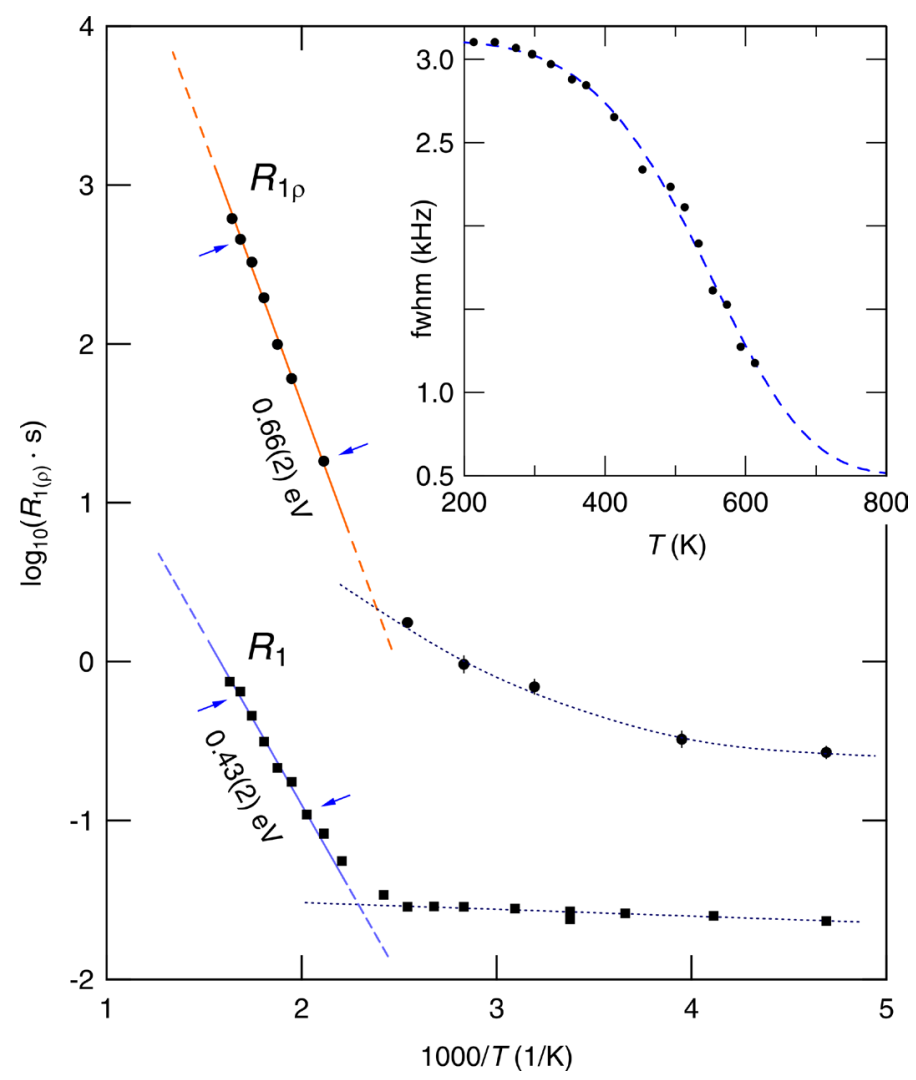

Fig. 6. Arrhenius plot of the ${ }^{7} \mathrm{Li}-\mathrm{NMR}$ SLR rates of $\mathrm{LiBi}_{3} \mathrm{~S}_{5}$ recorded in both the laboratory frame $\left(R_{1}, \mathbf{\square}\right)$ and in the rotating frame of reference $\left(R_{1 \rho}, \bullet\right)$. Data were measured at $\omega_{0} / 2 \pi=116.4 \mathrm{MHz}$. The locking frequency was $\omega_{1} / 2 \pi=20 \mathrm{kHz}$. Inset: ${ }^{7} \mathrm{Li}-\mathrm{NMR}$ line width (fwhm) as a function of temperature $T$. The dashed blue line is drawn to guide the eye. See text for further explanation.

In Fig. 6, the rates $R_{1}$ and $R_{1 \rho} v s$. the inverse temperature are shown as an Arrhenius plot. By increasing the temperature $T$, the rates pass over into the so-called low- $T$ flank of a diffusioninduced peak. Because of slow lithium-ion diffusion, the high- $T$ flank cannot be accessed below $600 \mathrm{~K}$. While the latter flank would entail information on long-range diffusion, the low- $T$ flank is affected by local, within-site ion dynamics, which can additionally be influenced by correlation effects such as Coulomb interactions and structural disorder [40]. Below $c a .400 \mathrm{~K}$, a non-diffusive background is observed, as indicated by the dotted line in Fig. 6. Most likely, it is caused by coupling of the lithium spins with conduction electrons, lattice vibrations, or by paramagnetic impurities. For $R_{1 \rho}$, the same two regions can be seen. Noticeably, almost temperature-independent background relaxation of spin-lock NMR shows up below $250 \mathrm{~K}$. Between temperatures of 250 and $400 \mathrm{~K}$, a slight increase of $R_{1 \rho}$ is observed that is, however, absent in $R_{1}$. 
The solid lines in Fig. 6 represent Arrhenius fits. The range of data points used for the fitting procedure is marked by the arrows drawn. While in the case of $R_{1}$ the activation energy turned out to be $E_{\mathrm{a}}=0.43(2) \mathrm{eV}$, a value of $E_{\mathrm{a}}=0.66(2) \mathrm{eV}$ is obtained for $R_{1 \rho}$. As mentioned above, the rates $R_{1 \rho}$ are more sensitive to long-range lithium-ion motions rather than to short-range ion dynamics. The discrepancy seen in $E_{\mathrm{a}}$ hints at correlated ion dynamics and multiple-jump pathways the ions have access to.

Compared to investigations of other lithium-containing sulfides (see, e.g., refs. [41,11]), the ${ }^{7} \mathrm{Li}-\mathrm{NMR}$ measurements identified $\mathrm{LiBi}_{3} \mathrm{~S}_{5}$ as a poor lithium-ion conductor. The activation energy of $0.66 \mathrm{eV}$ is two to three times larger than the ones usually found for sulfides exhibiting extremely fast ion exchange $(0.2-0.3 \mathrm{eV})$ [40,42]. Slow ion dynamics also manifests in rather low $R_{1}$ rates measured near ambient temperature: rates in the order of $0.025 \mathrm{~s}^{-1}$ in combination with the temperature independence seen in this $T$ range clearly indicate slow lithium-ion diffusivity. Of course, the absolute value depends on the number density of paramagnetic impurities of the sample, which, in our case, seems to be rather low.

The very slow ion dynamics can be understood in terms of spatially restricted lithium diffusion. As already suggested above, $\mathrm{LiB}_{3} \mathrm{~S}_{5}$ proved to conduct lithium-ion along the channels in the $b$ direction. Any blockade of these by immobile bismuth ions, as verified to be present by neutron diffraction, greatly slows down lithium self-diffusivity in the material. Such a decrease is expected for 1D ion conductors, which are prone to clogging [43]. Even in the case of accessible channels, highly correlated motion is anticipated for materials only offering spatially restricted $1 \mathrm{D}$ pathways, i.e., single-file diffusion in narrow channels.

\section{Conclusions}

We have successfully synthesized grey-black $\mathrm{LiBi}_{3} \mathrm{~S}_{5}$ as pure-phase material using a solidstate reaction. The ternary sulfide crystallizes in a variant of the known $\mathrm{AgBi}_{3} \mathrm{~S}_{5}$ type with a highly disordered cation sublattice. A closer look at the coordination polyhedra in this quite complex material offers explanations, why some positions are preferred by one or the other type of cation.

Topological methods based on the Rietveld-refined model suggest that $\mathrm{LiBi}_{3} \mathrm{~S}_{5}$ is indeed a $1 \mathrm{D}$ lithium-ion conductor. Defects in the cation lattice can be formed by displacement of lithium ions into tetrahedral voids. Migration can only occur along channels in the $b$ direction that are 
situated in the transition zone between the slabs and comprise the positions $\mathrm{Bi} 5 / \mathrm{Li} 5$. The curved migration pathway traverses a tetrahedral void and is blocked in the presence of a bismuth ion. As seen via NMR, spatial restriction results in low lithium-ion diffusivity. Motional processes occurring on long-range as well as short-range scales were probed through ${ }^{7} \mathrm{Li}-\mathrm{NMR}$ relaxometry. In particular, activation energies as high as $0.66(2) \mathrm{eV}$ were extracted from spin-lock NMR. This finding is in line with results from NMR motional line narrowing hinting at a lithium jump-rate in the order of $c a .2 \times 10^{4} \mathrm{~s}^{-1}$ at $500 \mathrm{~K}$. Such values clearly identify $\mathrm{LiBi}_{3} \mathrm{~S}_{5}$ as a moderate, if not poor ionic conductor. These findings are in line with studies on the channel-structured quaternary sulfide $\mathrm{LiPbSb}_{3} \mathrm{~S}_{6}$, in which cation disorder accounts for low thermal diffusivity and conductivity [44].

In general, synthesis starting from $\mathrm{LiBiS}_{2}$ and $\mathrm{Bi}_{2} \mathrm{~S}_{3}$ can be considered a promising route to new lithium bismuth sulfides with structure types known from the pavonite homologous series.

\section{Acknowledgments}

The authors would like to thank Dr. Rafael Zubrzycki and Dipl.-Chem. Steven Orthmann (Technische Universität Berlin) for performing XRF and oxygen analyses, respectively. M.W. would like to thank Oliver Steiner and Dr. Walter Gössler for the metal determination as well as the Austrian Federal Ministry of Economy, Family and Youth, and the Austrian National Foundation for Research, Technology and Development for financial support.

This work is based upon experiments performed at the SPODI instrument operated by FRM II at the Heinz Maier-Leibnitz Zentrum (MLZ), Garching b. München, Germany. Financial support by the Deutsche Forschungsgemeinschaft (FOR 1277: "Mobilität von Lithiumionen in Festkörpern [molife]") is gratefully acknowledged.

\section{References}

[1] D.M. Rowe (Ed.), Thermoelectrics Handbook: Macro to Nano, CRC Press, Boca Raton, USA, 2006.

[2] (a) M.J. Smith, R.J. Knight, C.W. Spencer, J. Appl. Phys. 33 (1962) 2186-2190; (b)

L.R. Testardi, J.N. Bierly Jr., F.J. Donahoe, J. Phys. Chem. Solids 23 (1962) 1209- 
1217; (c) C.H. Champness, P.T. Chiang, P. Parekh, Can. J. Phys. 43 (1965) 653-569;

(d) W.M. Yim, E.V. Fitzke, J. Electrochem. Soc. 115 (1968) 556-560.

[3] (a) M.G. Kanatzidis, Semicond. Semimet. 69 (2001) 51-100; (b) D.-Y. Chung, L. Iordanidis, K.-S. Choi, M.G. Kanatzidis, Bull. Korean Chem. Soc. 19 (1998) 12831293; (c) M.G. Kanatzidis, S.D. Mahanti, T.P. Hogan, Chemistry, Physics and Materials Science of Thermoelectric Materials: Beyond Bismuth Telluride, Kluwer Academic/Plenum Publishers, New York, USA, 2003, p. 35; (d) A. Mrotzek, M.G. Kanatzidis, Acc. Chem. Res. 36 (2003) 111-119.

[4] D.-Y. Chung, K.-S. Choi, L. Iordanidis, J.L. Schindler, P.W. Brazis, C.R. Kannewurf, B. Chen, S. Hu, C. Uher, M.G. Kanatzidis, Chem. Mater. 9 (1997) 3060-3071.

[5] L. Iordanidis, P.W. Brazis, T. Kyratsi, J. Ireland, M. Lane, C.R. Kannewurf, W. Chen, J.S. Dyck, C. Uher, N.A. Ghelani, T. Hogan, M.G. Kanatzidis, Chem. Mater. 13 (2001) $622-633$.

[6] D.-Y. Chung, T. Hogan, P.W. Brazis, C.R. Kannewurf, M. Bastea, C. Uher, M.G. Kanatzidis, Science 287 (2000) 1024-1027.

[7] T.J. McCarthy, S.-P. Ngeyi, J.-H. Liao, D. DeGroot, T. Hogan, C.R. Kannewurf, M.G. Kanatzidis, Chem. Mater. 5 (1993) 331-340.

[8] L. Iordanidis; D. Bilc, S.D. Mahanti, M.G. Kanatzidis, J. Am. Chem. Soc.125 (2003) 13741-13752.

[9] T.J. McCarthy, T.A. Tanzer, M.G. Kanatzidis, J. Am. Chem. Soc. 117 (1995) 12941301.

[10] K. Chondroudis, M.G. Kanatzidis, J. Solid State Chem. 136 (1998) 328-332.

[11] V.B. Lazarev, S.I. Berul', A.F. Trippel', Russ. J. Inorg. Chem. 22 (1977) 1218-1220.

[12] V. Epp, O. Gün, H.-J. Deiseroth, M. Wilkening, J. Phys. Chem. Lett. 4 (2013) 2118 2123.

[13] M. Hoelzel, A. Senyshyn, O. Dolotko, J. Large-Scale Res. Facil. 1 (2015) A5.

[14] M. Hoelzel, A. Senyshyn, N. Juenke, H. Boysen, W. Schmahl, H. Fuess, Nucl. Instrum. Methods Phys. Res., Sect. A 667 (2012) 32-37.

[15] E. Makovicky, W.G. Mumme, J.A. Watts, Can. Mineral. 15 (1977) 339-348.

[16] G. Bergerhoff, I.D. Brown, Inorganic Crystal Structure Database, in: F.H. Allen, G. Bergerhoff, R. Sievers (Eds.), Crystallographic Databases, International Union of Crystallography, Chester, UK, 1987, pp. 77-95.

[17] J. Rodríguez-Carvajal, Phys. B: Condens. Matter 192 (1993) 55-69.

[18] J.-F. Bérar, G. Baldinozzi, J. Appl. Crystallogr. 26 (1993) 128-129. 
[19] K. Brandenburg, H. Putz, DiAmond 3.2 - Crystal and Molecular Structure Visualization, Crystal Impact, Bonn, Germany, 2014.

[20] S.K. Wolff, D.J. Grimwood, J.J. McKinnon, M.J. Turner, D. Jayatilaka, M.A. Spackman, CRYSTALEXPLORER 3.1 - Crystal Structure Analysis with Hirshfeld Surfaces, University of Western Australia, Perth, Australia, 2012.

[21] V.A. Blatov, A.P. Shevchenko, D.M. Proserpio, Cryst. Growth Des. 14 (2014) 35763586.

[22] As the spherical-domain radius for lithium ions in sulfides has not yet been established, it was estimated enlarging the value for oxides $\left(R_{\mathrm{sd}}=138 \mathrm{pm}\right)$ by $20 \mathrm{pm}$, an average difference for other cations known in both environments; V.A. Blatov, Crystallogr. Rev. 10 (2004) 249-318.

[23] R.D. Shannon, Acta Crystallogr., Sect. A: Cryst. Phys., Diffr., Theor. Gen. Crystallogr. 32 (1976) 751-767.

[24] V.A. Blatov, G.D. Ilyushin, O.A. Blatova, N.A. Anurova, A.K. Ivanov-Schits, L.N. Dem'yanets, Acta Crystallogr., Sect. B: Struct. Sci. 62 (2006) 1010-1018.

[25] H. Zabrodsky, S. Peleg, D. Avnir, J. Am. Chem. Soc. 114 (1992) 7843-7851.

[26] O. Glemser, M. Filcek, Z. Anorg. Allg. Chem. 279 (1955) 321-323.

[27] C. Long, H. Fan, M. Li, Dalton Trans. 42 (2013) 3561-3570.

[28] B. Hamdi, H.E. Feki, J.-M. Savariault, A.B. Salah, Mater. Res. Bull. 42 (2007) 299311.

[29] A. Zayit, M. Pinsky, H. Elgavi, C. Dryzun, D. Avnir, Chirality 23 (2011) 17-23.

[30] D. Wiedemann, M.M. Islam, S. Nakhal, A. Senyshyn, T. Bredow, M. Lerch, J. Phys. Chem. C 119 (2015) 11370-11381.

[31] D. Wiedemann, S. Nakhal, J. Rahn, E. Witt, M.M. Islam, S. Zander, P. Heitjans, H. Schmidt, T. Bredow, M. Wilkening, M. Lerch, Chem. Mater. (2016) doi:10.1021/acs.chemmater.5b04608.

[32] M.Ø. Filsø, M.J. Turner, G.V. Gibbs, S. Adams, M.A. Spackman, B.B. Iversen, Chem. Eur. J. 19 (2013) 15535-15544.

[33] M. Wilkening, V. Epp, A. Feldhoff, P. Heitjans, J. Phys. Chem. C 112 (2008) 92919300.

[34] M. Wilkening, A. Kuhn, P. Heitjans, Phys. Rev. B 78 (2008) 054303.

[35] A. Kuhn, S. Narayanan, L. Spencer, G. Goward, V. Thangadurai, M. Wilkening, Phys. Rev. B 83 (2011) 094302.

[36] D. Ailion, C. Slichter, Phys. Rev. Lett. 12 (1964) 168-171. 
[37] C. Slichter, D. Ailion, Phys. Rev. A 135 (1964) 1099-1110.

[38] D. Wolf, Phys. Rev. B. 10 (1974) 2724-2732.

[39] W. Schmidt, P. Bottke, M. Sternad, P. Gollob, V. Hennige, M. Wilkening, Chem. Mater. 27 (2015) 1740-1750.

[40] M. Wilkening, P. Heitjans, Chem. Phys. Chem. 13 (2012) 53-65.

[41] B. Stanje, V. Epp, S. Nakhal, M. Lerch, M. Wilkening, ACS Appl. Mater. Interfaces 7 (2015) 4089-4099.

[42] D. Wohlmuth, V. Epp, M. Wilkening, ChemPhysChem 16 (2015) 2582-2593.

[43] V. Epp, M. Wilkening, Phys. Rev. B 82 (2010) 020301.

[44] E.C. Agha, C.D. Malliakas, J. Im, H. Jin, L.-D. Zhao, A.J. Freeman, M.G. Kanatzidis, Inorg. Chem. 53 (2014) 673-675. 